\title{
Research Issues on Customer-Oriented and Eco-friendly Networks for Healthy Fashionable Goods
}

\author{
Rosanna Fornasiero $^{1}$, Andrea Chiodi $^{2}$, Emanuele Carpanzano $^{1}$, and Luis Carneiro ${ }^{3}$ \\ ${ }^{1}$ ITIA-CNR, Via Bassini, 15 \\ 20133 Milano-Italy \\ \{rosanna.fornasiero, emanuele.carpanzano\}@itia.cnr.it \\ ${ }^{2}$ Synesis Consortium \\ Milano-Italy \\ andrea.chiodi@synesis-consortium.eu \\ ${ }^{3}$ Inesc Porto-FEUP campus, Rua Dr. Roberto Frias, 378 \\ 4200 - 465 Porto-Portugal \\ luis.carneiro@inescporto.pt
}

\begin{abstract}
Needs and expectations of specific target groups - such as elderly, obese, disabled, or diabetic persons- are arising as challenging opportunities for European companies which are asked to supply small series of functional and fashionable goods of high quality, affordable price and eco-compatible. In order to design, develop, produce and distribute such products, a new framework and related components of collaborative networking need to be developed, enabling the product to stay as long as digital to produce on-demand. Research is necessary in many topics like: a) consumer integrated collaborative eco-oriented design, b) radical renewal by the adoption of Rapid Manufacturing technologies; and c) the overall integration and co-ordination of business processes and information exchange by a set of new (web)services for network design and adhoc (re-)configuration, for real-time planning, forecasting and replenishment, d) tracking and tracing of ecology and quality.
\end{abstract}

Keywords: supply chain, consumer goods, sustainability.

\section{Introduction}

In recent years, it is emerging at industrial level that full adoption of methodologies and technologies for collaborative production of small series are of decisive importance for European Manufacturing Industry, SMEs in particular, to proactively respond to the high variability of consumers demand and expectations. This will help reducing the risks of following fast changing trends without appropriate tools, causing serious limits in terms of both customer satisfaction and enterprise competitiveness and sustainability.

This is especially true in consumer goods sectors, where customer's tastes change very quickly, especially in the current economic situation of downturn, where the 
purchase capability of customers has sharply decreased and companies need to strongly focus on high value products.

In this work, consumer goods and in particular shoes are considered. In the last years, in footwear industry, on one hand, the number of seasonal collections has been increasing, enlarging the offer in terms of models along the year, and on the other hand the number of products per model has been decreasing in major markets, leaving best opportunities only for companies producing value added and wide range of products.

Moreover, social phenomena like ageing, increase of obese and disabled people [1] and major sensitivity versus eco-friendly products are also key challenges to be faced by the considered consumer sectors, with reference to healthcare and sustainability [2]. As a matter of fact, today consumers demand for personalization and value adding of harmonized footwear products, as well as in the textile and clothing industry, is not only in terms of aesthetics, but also in terms of health, innovative functionalities and environmental sustainability. Consumers want to know where the product comes from, how it has been created and how it will satisfy his needs and provide health and well being.

There is a clear need for health fashionable consumer goods, since customers today want to be fully satisfied both in their look and their health, but also demand for personalized solutions for their individual needs. The compromise that fashion products may not be healthy and that healthy products may not be fashionable is not going to be accepted anymore by a changing society with increasing needs and expectations and there is a niche market especially for categories like the one mentioned before (seniors, disables, obese people) where European companies can find their way to better satisfy the customer.

This implies small series production with fast delivery which cannot face long waiting time for materials, components and manufacturing services, and a new way to structure the supply network is needed [3]. Production lines and equipments need to be changed to meet such challenging requirements [4].

Open research issues need to address the design, production as well as supply and distribution of small series of health fashionable goods for specific target groups of wide impact in terms of market for the European industry as elderly, disables, diabetics and obese people through personalized and comfortable shoes (e.g. anallergic and bio materials, reduced stitching, flexible and light components) with dedicated medial insoles for foot measurement. Solutions should be based on cost, social compliance and eco-efficient design and production of customised products that fully satisfy the customers considering their health as well as their desire for fashionable products.

\section{State of the Art}

There are different categories of research topics to be investigated to offer a complete solution to support companies in answering and/or anticipating customer needs. Dimensions to be considered cover many different aspects of production management from organizational changes, to ICT for design and production collaboration, to new production systems and to Supply Chain management. 


\subsection{Frameworks for Sustainable Networks}

From the organizational point of view, companies are facing a new level of complexity, given by the fact that competition as well as collaboration schemes are transitioning from among companies to among supply networks.

In literature, different forms and specifications of business networks are discussed. They are distinguished for example by value chain orientation (horizontal, vertical, lateral), life span duration (long-term vs. short-term), degree of virtualization or hierarchical structure (hierarchical vs. non-hierarchical networks) [5]. While most reallife business networks are formed along the value chain and for long-time purpose, the current market asks for flexible organizational structures which can quickly adapt to new prerequisites and challenges.

The new paradigm of Demand-driven supply networks is emerging in literature as a collaborative scheme in response to consumers direct signals and needs [6] and [7]. This implies different approaches to the market based not only on traditional sales channels (shops, retailers) but more and more on an Internet mediated direct contact with consumers both for product conception and for product sales.

For production aspects, as partners are locally dispersed, and processes are knowledge-intensive, the paradigm of Smart Organizations [8], which is based on concepts like the Extended Enterprise, (Dynamic) Virtual Organization and Virtual Breeding Environment, need to be transferred to hybrid and disomogeneuos networks where footwear companies integrate their production with other companies to offer to the customer solutions embedded with high tech devices [5]. Collaboration will not only be regarded in the perspective of organizational networking, but also in terms of networking ICT support to achieve strategic goals like resource optimization, synergy creation, the achievement of a critical mass and increased benefit for all partners [9], [5].

\subsection{Knowledge Management in Networks}

Recent literature on knowledge sharing in networks is based on:

- hybrid centralized-decentralized models for data and services to allow private confidential data (like Design data) to be kept by the owner and less private, commercial and collaboration data, to be stored in third party data-service centers, thanks to the new IoS technologies of ICT resources virtualization (i.e. Cloud Computing);

- value added services provided by reliable service centers set up and maintained by IT professionals, while Utility Services (like interoperability and collaboration services) offered by distributed service centers based on the existing infrastructure (like COIN $^{1}$ proposes);

- real time data capture from the field provided by Open Source platforms (like ASPIRE) also to allow the acquisition of eco-compatible data series.

\footnotetext{
${ }^{1}$ Collaboration and interoperability for networked enterprises, FP7-ICT-2007.1.3-216256, http://www.coin-ip.eu
} 


\subsection{Co-design and Sustainability}

Today product co-design tools commercially available do not either encapsulate customer orientation as a common feature or foresee real interoperability for an effective distribution of the design phase along the chain. Considering solutions developed within past and ongoing projects, only some steps within customization domain are covered (see for example EUROShoE project ${ }^{2}$ and CEC-made-shoe project ${ }^{3}$ results for CAD).

Another aspect to be considered during design phase is the evaluation of environmental impact of products and processes for each shoe model to be developed and for each collection. Shoes are complex products in terms of their environmental impacts: combination of constituting materials and short use time lifecycle result as critical factors able to increase dramatically the environmental burden. Every year nearly 12 million of shoes are sent in landfill with minimal possibilities of recovery contributing to increase the whole amount of not recyclable waste.

At present, a number of environmental standards provide partial information on process related to product (ISO labels, Ecolabel and Environmental Product Declaration) with a common weak point, such as lack of adequate quantitative information in order to compare different products identified as environmental friendly, or possible hidden steps in product conditions.

Designers suffer from a scarcity in tools and methodologies in order to evaluate easily the impact related to design choices in advance. Current tools are frequently too expensive and not suitable for the use within firms especially within SMEs. The main barrier is the high level of customization and changeability of such products. For each firm, the whole portfolio may include several hundred of models each requiring specific materials and modifications. The introduction of new advanced materials in place of traditional materials introduces a further complexity in impact assessment.

\subsection{Methods and Tools for Co-planning Production and Distribution}

Small series and personalized products require totally different supply network structures, having to be configured for each customer order and including small number of companies chosen in a large number of accredited potential partners. In practice scenarios will be characterized by a very large number of small orders, each of them having different partner companies, based on their availability and capabilities. In this context, new co-planning systems will be required to optimize the production plans that result, on a first iteration, from the configuration (or set up) of the supply network for each order. Distribution emerges to be different from the one for traditional products and has to be faster and more flexible, assuring that each product is mainly directed to the sales point where best fits the local customer preferences.

\footnotetext{
${ }^{2}$ EUROSHOE project, EU VFP.

${ }^{3}$ CEC-made-shoe project, EU VIFP mass-customization.blogs.com/.../the-cec-co-design-contestopen-innovation-in-the-footwear-industry.html
} 
The complex planning problems arising in the context of collaborative networks is based on the broad class of "Combinatorial Optimization" and for tackling hard problems, it is possible to use state-of-the art metaheuristics. These are reasonably simple and flexible optimization algorithms based on local search procedures, and in general quite easily adaptable to cope with new problem configurations.

The "classical metaheuristics" (Simulated Annealing, tabu search and Genetic Algorithms) have evolved to more refined methods, and also have given rise to new methodologies like Variable Neighbourhood Search (VNS), Greedy Randomized Adaptive Search Procedure (GRASP), Ant Colonies Optimization, etc. [10], [11].

A recent, extension of these approaches is on the design of multi-objective metaheuristics, thus incorporating some critical requirements of practical problems. These approaches are presenting very promising results in several areas and expected to be key in the successful resolution of optimization [12], [13], [14].

\section{The Proposed Approach}

Future research for healthy fashionable products need to be based on the following pillars:

\section{P1. Reference Framework for Collaborative Supply Networks}

The reference framework model for collaborative supply networks shall address, orientate and integrate all aspects both at organizational and technological level concerning interaction of organizations, business processes, considering co-ordination and synchronisation of contents, as well as information exchange and software application modularity for improvements in data management, in order to create a seamless flow of information from market to design and development, to production and distribution.

From the organizational point of view the following topics will be considered to implement an innovative model for footwear collaborative supply networks:

- Hierarchical vs. not-hierarchical supply chains

- Business ecosystems vs. smart organizations

- Agile and proactive Virtual Organisations creation, management and governance

- Social networking, Consumer Communities and Living Labs as vehicles for customer/consumer integration in the context of OpenInnovation.

From the technological point of view, the reference data model shall be based on service interoperability defined as a backbone for the development of the related applications in the following pillars. Particular attention will be given to the integration of the new services in already existing solutions in order to avoid replication and overlapping with existing systems. 


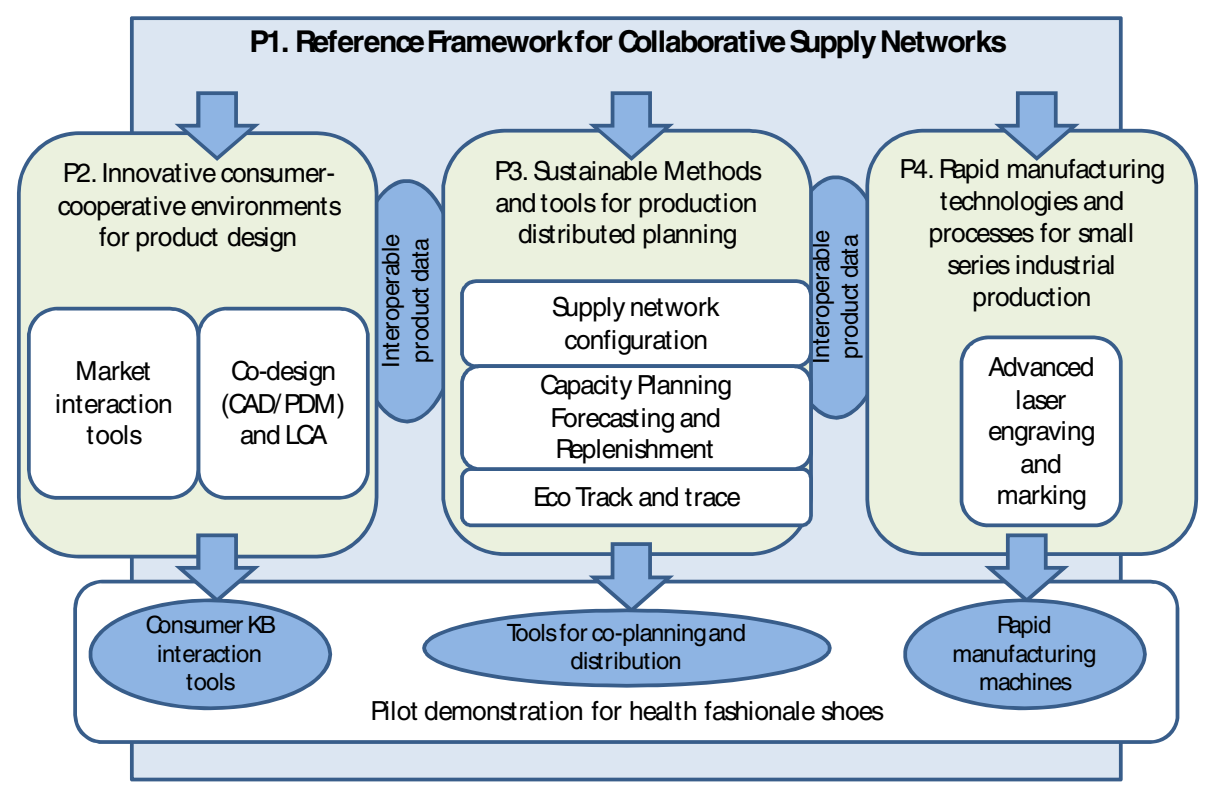

\section{P2. Innovative consumer-driven environments for product design}

This pillar will address the implementation of innovative environments for consumers and suppliers collaboration and knowledge management. The goal is to create a novel concept that enables the vision of an "empowered-to-design" consumer from one side, and the creation of market and design knowledge within a social network environment [15].

This pillar aims thus to achieve cutting edge innovation along the following lines:

- Collaborative design tools, empowering the consumers to design their own products by providing them the ability to collaborate in an informed design process not only regarding aesthetics, prices and delivery times, but also regarding resources consumption and social responsibility, implementing sustainability parameters in the design phase and relying on the synchronization of the design along the supply chain;

- A new model of market information sourced from the unstructured information from consumers, designers and suppliers interaction, within a social network/virtual community environment and relying upon the use of semantic technologies for knowledge extraction and pattern matching [16], [17].

Multifunctional design need to be supported by an event driven tool for the coordination of design and industrialization phases with production process. Intelligent tools for product and components design is necessary to plan the ecological, economical and social sustainability of each model based on innovative approach to LCA-Life Cycle Analysis. All of these should be developed as plug-ins and additional services for existing enterprise applications (CAD-PDM solutions).

This pillar need to study how to manage market and product data to define not only "customer-" but also "market virtual profile" and how to use this data during design process. Information on consumers to capture requirements on style preferences, 
physical measure, health needs and feedback on product previous versions, through implementation of consumer communities, web spaces for customers feedback, "point of opinion" at retailers stores, configurators capable of managing personalized data.

\section{P3. Methods and tools for supply network configuration and distributed produc- tion planning}

In this pillar, innovative and adaptive services for production process modeling and supply networks formation and management shall be based on a distributed interaction system to integrate different actors (components suppliers, outsourcers, service providers, retailers, customers) of different sectors collaborating in dynamic networks. Moreover product and process quality control based on environmental impact parameters shall be developed through a shared platform for eco-monitoring.

Main contribution in this pillar shall be based on developing innovative services for supply network management based on existing technologies like SOA, EDA, Product Tracking \& Tracing, web2.0, semantic web ${ }^{4}$ and existing commercial applications.

In particular it will be important to develop the following three services:

- Easy-to-use Supply \& Distribution Network Design (SDND) Service for configuring supply networks, based on full sustainability parameters. Life Cycle Costing tool for supply networks can be used to evaluate the sustainability impact of each of the possible network configurations according to a peer-to-peer distributed data set published autonomously by each potential supplier. Particular attention need to be paid to cross-domain collaborative processes support and fast changing networks. Companies need to share a reference and extensible competences model, which captures comprehensive relevant information and knowledge to maximize end-to-end visibility related to suppliers, distributors, third party logistics providers, based on Availability-to- promise and Capacity-to-promise data.

- User-friendly Collaborative Planning Forecasting and Replenishment (CPFR) Service, based on ad-hoc combinations of optimization algorithms shall be studied and implemented to guarantee on-time delivery based on optimization of the trade-off between minimization of cost and lead time, quality and customer service. The systems shall be based on real-time product tracking and tracing data, captured from distribution centers, from third party logistics providers and data from producers. Supply and Distribution processes will be managed in a decentralized way allowing the partners of the value network to choose the best option for on-time delivery. New models shall be studied to merge delivery from different producers.

- A web- and wireless- enabled Eco- and Quality- Monitoring service on product/process quality and eco-sustainability along the value chain, to collect information for producers and customers on who, how, where, when, the product was produced and delivered indicating a level of sustainability and product quality.

Such services will be made available for integration into state-of-the-art existing SCM systems, either as plug-ins or as external services to be called on-demand.

${ }^{4}$ Under development in ICT projects like COIN (IP www.coin-ip.eu) and iSURF (STREP http://www.srdc.com.tr/isurf/) 


\section{P4. Rapid manufacturing technologies for small series industrial production}

Rapid manufacturing technologies shall enable the flexible, energy and eco-efficient production of specific added value components/parts of consumer personalized goods [18]. In particular reduction of set-up time is crucial in the production of small series in order to avoid loss of time when changing models. Cutting-edge technologies for developing a multi-process machine based on laser decoration and engraving for production of small series specifically developed as a unique integrated unit coping with high speed laser cutting, laser engraving, laser marking for personalized shoes.

These four pillars should be integrated in a unique solution and demonstrators need to be implemented to test and validate pilot collaborative supply network offering integrated small series of personalized shoes to target groups. Pilot demonstrators shall be composed of manufacturing companies collaborating with technologies providers along product lifecycle where coordination has to be managed at supply chain level.

\section{Conclusions}

The proposed approach to support footwear companies in the implementation of new models for small series production for health and fashionable goods follows the Competitive Sustainable Manufacturing (CSM) paradigm [19] and current initiatives of European Technological Platforms like Manufuture [20] and Footwear [21] asking to join forces for strengthening the European manufacturing sectors for the benefit of the European industry and of the final customer.

This means that sustainability is interpreted in the European STEEP (Social Technological Economical Environmental Political) sense to include in strategy definition: globalisation of the economy, climate change, ageing population, public health for all, poverty and social exclusion, loss of biodiversity, increasing waste volumes, soil lost and transport congestion [19].

In this context, the specific objective of new research shall be to increase significantly the sustainability of value creation of small series health fashionable consumer goods and in particular of footwear products, for emerging social by systemic/coordinated intra- and inter-sector networking of producers/service providers using cutting-edge (digital and) production technologies and as well as innovative organizational models based on cross-supply network integration through major complementary breakthrough innovations.

\section{References}

1. DG Employment: Europe's demographic future: Facts and figures on challenges and opportunities, European Commission, DG for Employment, Social Affairs and Equal Opportunities (2007), http://ec.europa.eu/employment_social/spsi/docs/ social_situation/demo_report_2007_en.pdf

2. EU Commission White Paper on Health Together for Health:A Strategic Approach for the EU 2008-2013 (2007), http://ec.europa.eu/health/ph_overview/ strategy/health_strategy_en.htm 
3. Fornasiero, R., Tescaro, M., Scarso, E., Gottardi, G.: How to Increase Value in the Footwear Supply Chain. In: Camarinha-Matos, L.M., Paraskakis, I., Afsarmanesh, H. (eds.) Leveraging Knowledge for Innovation in Collaborative Networks, Proceedings of the 10th IFIP WG 5.5 Working Conference on Virtual Enterprises, PRO-VE 2009, IFIP Advances in Information and Communication Technology, Greece, October 7-9, vol. 307, pp. 527$536(2009)$

4. Carpanzano, E., Ballarino, A.: Collaborative networked enterprises: a pilot case in the footwear value chain. In: Azevedo, A. (ed.) Innovation in Manufacturing Networks. IFIP. Springer Series in Computer Science, pp. 57-66 (2008)

5. Camarinha-Matos, L.M., Picard, W.: Pervasive Collaborative Networks. In: IFIP TC 5 WG 5.5 Ninth Working Conference on Virtual Enterprises, IFIP Advances in Information and Communication Technology, vol. 283 (2008), ISBN: 978-0-387-84836-5

6. Childerhouse, P., Aitken, J., Towill, D.R.: Analysis and design of focused demand chains. Journal of Operations Management 20(6), 675-689 (2002)

7. De Treville, S., Shapiro, R.D., Hameri, A.-P.: From supply chain to demand chain: the role of lead time reduction in improving demand chain performance. Journal of Operations Management 21(6), 613-627 (2004)

8. Filos, E.: Smart Organizations in the Digital Age. In: Integration of Information and Communication Technologies in Smart Organizations, pp. 1-38. Hershey Idea Group Publishing (2006)

9. Camarinha-Matos, L.: Virtual Enterprises and Collaborative Networks, Boston (2004)

10. Resende, M.G.C., Sousa, J.P.: Metaheuristics: Computer Decision-Making. Kluwer, Dordrecht (2004), ISBN 1-4020-7653-3

11. Glover, F., Laguna, M.: Tabu search. Kluwer Academic Publishers, Boston (1997)

12. Azevedo, A.L., Toscano, C.A.M., Sousa, J.M.P., Soares, A.L.: An Advanced Agent-Based Order Planning System for Dynamic Networked Enterprises. Production Planning \& Control, special issue on Management of Operations 15(2), 133-144 (2004)

13. Blum, C., Roli, A.: Hybrid Metaheuristics: An Introduction. Studies in Computational Intelligence, vol. 114. Springer, Heidelberg (2008), ISSN 1860-9503

14. Siarry, P., Michalewicz, Z. (eds.): Advances in Metaheuristics for Hard Optimization. Natural Computing Series. Springer, Heidelberg (2008), ISBN 978-3-540-72959-4

15. Hendrickson, M.: TechCrunch. Nine Ways to Build Your Own Social Network (July 2007), http: / /www. techcrunch.com/2007/07/24/

9-ways-to-build-your-own-social-network/

16. Lea, B., Yu, W., Maguluru, N., Nichols, M.: Enhancing business networks using social network based virtual communities. Industrial Management \& Data Systems 106(1), 121138 (2006)

17. Boulton, C.: eWeek.com. Consolidation Time for White-label Social Networks (2008), http: / /www. eweek.com/c/a/Messaging-and-Collaboration/ Consolidation-Time-for-Whitelabel-Social-Networks /

18. Carpanzano, E., Ballarino, A., Jovane, F.: Towards the New Mass Customisation and Personalisation Paradigm: Needed Next Generation Manufacturing Technologies. In: Proc. 40th Cirp International Seminar on Manufacturing Systems, Liverpool, May 30-June 1 (2007)

19. FoF-PPP: Factories of the Future: Public, Private Partnership, Strategic Multi-annual Roadmap (2009)

20. Manufuture, Strategic Research Agenda (2006)

21. ETP-Footwear: Vision and Strategic Research Agenda of the European Footwear Products and Processes Technology Platform (2006) 